\title{
The Application of Hyperspectral Sensing Data for Seabed Classification in the Coastal Area of Korea
}

\section{Dongha Lee ${ }^{1}$ and Sunhui Sim ${ }^{1, *}$}

1 Department of Geography, University of North Alabama, Florence, AL 35632-0001, U.S.A.; EMails: dlee2@una.edu (D.L.); ssim@una.edu (S.S.)

* Author to whom correspondence should be addressed; E-Mail: ssim@una.edu(S.S.); Tel.: +1-256765-4250; Fax: +1-256-765-4246.

Published: 1 June 2014

\begin{abstract}
Seabed classification is the important part of current coastal research because it characterizes the seabed and its habitats. Seabed characterization makes the link between the classified area and the physical, geological, chemical or biological properties of seabed. This paper addresses the possibilities of the use of airborne hyperspectral sensing with a CASI-1500 sensor to map the seabed covers in the coastal area of Korea. After radiometric, geometric and atmospheric correction for the raw hyperspectral data, the classification was performed in three steps. Firstly, fourteen classes of seabed were identified using a unsupervised spectral angle mapping algorithm in combination with data collected by ground survey. Secondly, seabed mapping was performed for each class separately. Finally, an accuracy assessment of the seabed mapping results was performed using data from ground survey. The overall accuracy was $83 \%$ with a kappa coefficient of 0.76 . The results indicated that the hyperspectral sensing can help not only to classify the seabed material remotely and precisely, but also to construct the continuous geographical information for an effective management and conservation of the coastal area in Korea.
\end{abstract}

Keywords: Hyperspectral sensing; CASI-1500 sensor; Seabed classification; Spectral angle mapping algorithm; Coastal area in Korea

\section{Introduction}

Classification of seabed material is the important part of current coastal research because it is one route to characterizing the seabed and its habitats. Seabed characterization makes the link between the 
classified regions and the seabed physical, geological, chemical or biological properties [1]. The seabed classification is generally based on the direct ground surveying (or inspection) as called the ground truthing. This direct method, however, provides information only for the limited sites [2]. Recent developments of remote classification of seabed material using hyperspectral data which made it possible to obtain continuous information of seabed materials [3].

This paper addresses the possibilities of the use of airborne remote sensing with a CASI-1500 hyperspectral sensor to map the coverage and the topography of seabed material in the coastal area of Korea. From April to October in 2012, hyperspectral imagery was acquired with a CASI-1500 sensor from the entire study area at low tide. Hyperspectral images contain a reflectance spectrum for each pixel. The characteristics of this spectrum are influenced by the state, the composition, and the structure of the seabed material and topography [4].

\section{Data and Processing}

\subsection{Sensor Backgrounds and Hyperspectral Surveying}

All matter on the earth's surface interacts with sunlight to some degree, reflecting, transmitting, or absorbing incident light based in part on material composition and structure, and influenced by biological activity $[4,5]$. It is the relative (and often subtle) differences in reflectance across the visible and near-infrared (VNIR) portions of the electromagnetic spectrum that provide the basis for the remote differentiation of surface materials in this region [6,7]. The commercial CASI (Compact Airborne Spectrographic Imager) series of hyperspectral VNIR imaging systems developed by ITRES Research Limited are calibrated remote sensing instruments designed to measure and record these spectral reflectance differences across the specified wavelength region [8].

Figure 1. Study area for seabed classification using hyperspectral data.

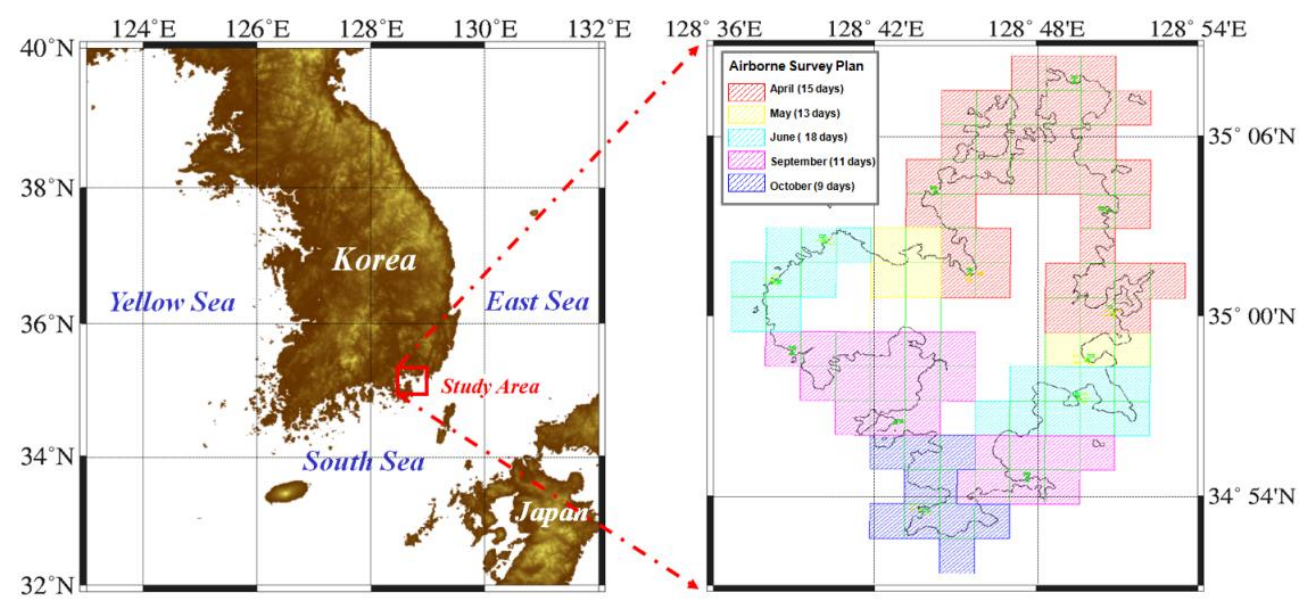

A CASI-1500 hyperspectral sensor consisting of an Instrument Control Unit (ICU), Sensor Head Unit (SHU), and monitor was employed for the hyperspectral surveying over study area for the seabed classification. The CASI-1500 system was integrated with a POSAV 410 Inertial Measurement Unit (IMU) that records aircraft motion (roll, pitch, and heading) using gyroscopes and accelerometers and that also records aircraft position using differential GPS [9]. 
After system mobilization and installation, two sets of survey flights were conducted. These were a geometric calibration survey flight for the bundle adjustment of raw data and the other was a survey project flights for seabed classification over the Geoje Island. A coastal area located in the Geoje island which is one of principal island on the southern coast of Korea is used as a study area for the seabed classification using hyperspectral image. Geoje Island covers an area of $383.44 \mathrm{~km} 2$ with $288.74 \mathrm{~km}$ of coastal line, the second largest island in South Korea (see Figure 1).

\subsection{Pre-Processing of Hyperspectral Data}

A single calibration flight was conducted over the Chanun calibration site on October 26, 2010 after sensor installation. The actual flight path over the boresite consisted of four East-West lines and four North-South lines. The data from this flight was used to determine the linear and angular offsets between the CASI-1500 and the co-mounted sensors (POSAV 410 and GPS) using ITRES bundle adjustment software [8, 10]. This allowed for measurements made by the IMU and GPS to be referenced to the co-mounted CASI SHU during post-processing, thereby increasing geometric accuracy in the final georeferenced imagery [9]. The installation and internal sensor offsets determined from this calibration site were applied in the geocorrection process to all imagery collected during the installation of the CASI system.

Hyperspectral data were acquired over the study area between April 2010 and October 2010 for the seabed classification. The operational sensor configurations for the airborne surveying are summarized in Table 1. As the evaluation of CASI system performance was the primary focus of this surveying, the final data were thus flown under optimal conditions in order to maximize data quality [8].

Table 1. Summary of the hyperspectral sensors for airborne surveying.

\begin{tabular}{cll}
\hline Instrument & \multicolumn{1}{c}{ Purpose } & \multicolumn{1}{c}{ Description } \\
\hline CASI-1500 & Hyperspectral VNIR imaging & -48 bands across a spectral range of 361.64-1048.16 nm. \\
& Aircraft position measurements & \\
POSAV 410 & Integrated GPS/IMU & - Externally mounted on top of the CASI-1500 SHU \\
& Real-time differential GPS & \\
\hline
\end{tabular}

Standard processing of CASI hyperspectral data produces georeferenced, radiometrically corrected imagery. There are three major steps involved. The first is to apply radiometric calibrations to convert the raw digital numbers of the imagery into radiance values. The second step involves processing the attitude and positional measurements from the airborne inertial system and GPS to create a navigation file, which is then used in the third and final general processing step, where the CASI data is georeferenced using UTM coordinates in the WGS84 datum $[9,10]$. During the surveying, extensive ground survey data collections in support of the hyperspectral data takes were performed.

\subsection{Ground Survey Data}

Prior knowledge about seabed cover types is very important for accurately classifying hyperspectral data using an unsupervised classification algorithm [11]. Even though some seabed cover types in high spatial resolution imagery can be identified by visual interpretation, a ground survey to obtain seabed cover information was carried out during the same period of airborne survey, and this was very helpful 
for providing accurate prior knowledge about the different seabed cover types in the CASI hyperspectral data. A total of 139 accessible ground survey sites were surveyed with the GPS locations of the individual survey. These data, together with manual interpretation of the CASI images, were used to select high-quality sample pixels for the different seabed cover types.

\section{Results and Discussion}

\subsection{Endmember Selection}

A Spectral Angle Mapper (SAM) algorithm [11], being implemented in ENVI 5.0 software, was applied for seabed classification over the study area. The SAM is designed to classify hyperspectral image data using a set of reference spectra that define the classes [12].

To obtain accurate classification results using the SAM, the choice of adequate endmembers (reference spectra) is of major importance. The optimal endmember classes over the study area were defined on the basis of the collected ground survey data.

\subsection{Seabed Classification using ENVI}

ENVI 5.0 software contains an application called the Spectral Hourglass Wizard (SHW) which guides the user step-by-step through the ENVI hourglass processing flow to find and map image spectral endmembers from hyperspectral data [12].

The first step in the hourglass processing flow deals with the Minimum Noise Fraction (MNF) determination. The MNF is used to describe the inherent dimensionality of imaging data, to segregate and equalize the noise in the data, and to reduce the computational requirements for subsequent processing [11]. The second step of the hourglass processing flow contains functionalities to derive endmembers directly from the input dat. In a next step, the Pixel Purity Index (PPI) was calculated on the hypersectral data. This was done in order to identify additional endmembers beside the ones already identified from the ground surveying data. To calculate the PPI, the user needs to specify the number of iterations [11]. In this study, 5,000 iterations were performed to produce the accurate classification result.

Figure 2. Final map of seabed classification in the study area using hyperspectral data. (a) RGB image of hyperspectral data. (b) Map of seabed cover with shape file format.

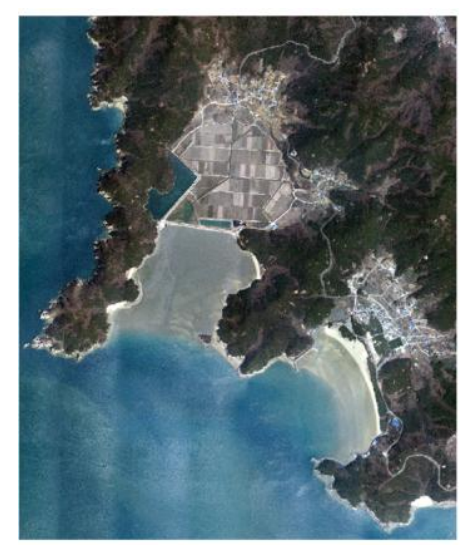

(a)

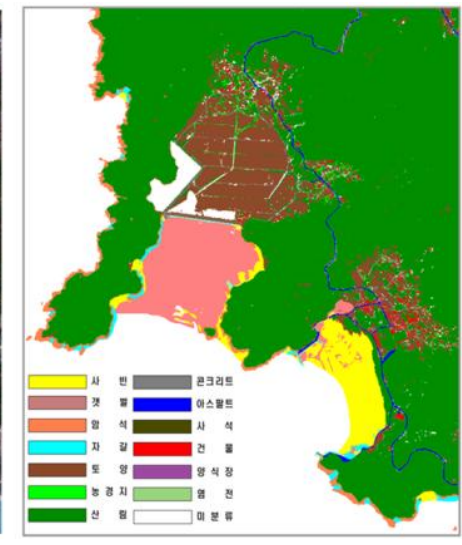

(b) 
The SAM classification is the last step in the SHW. The SAM output consists of a classification image and a set of rule images which correspond to the spectral angle calculated between each image pixel and each endmember. The best matches are the small angles. The classified seabed cover types using the CASI hyperspectral data were mapped according to the above hierarchical classification process [13], as illustrated in Figure 2.

\subsection{Accuracy Assessment}

In order to statistically differentiate between the CASI classification and ground survey results, accuracy assessments have to be performed. The accuracy assessments determine the correctness of classified images. The measure of accuracy is the correlation between a standard that is assumed to be correct and an image classification of unknown quality. In this study, the ground survey data consist of 139 verification samples which were set as point layers in the image file. The verification samples are used as a standard for the accuracy assessments of the classifications performed in ENVI 5.0 software.

The classification accuracy of the CASI hyperspectral data was assessed using the ground survey data and was found to have an overall accuracy of $83.07 \%$ and a kappa coefficient of 0.76 .

\section{Conclusions}

This paper addresses the possibilities of the use of airborne remote sensing with a CASI-1500 hyperspectral sensor to map the coverage and the topography of seabed material in the coastal area of Korea. From April to October in 2012, hyperspectral imagery was acquired at low tide. After radiometric, geometric and atmospheric correction for the raw images, the classification was performed in three steps. Firstly, ten classes of seabed were identified using a supervised spectral angle mapping algorithm in combination with data collected by ground survey. Secondly, seabed mapping was performed for each class separately using spectral and spatial information. Finally, an accuracy assessment of the mapping results was performed using data from field survey.

The overall accuracy was $83 \%$ with a kappa coefficient of 0.76 . The results indicated that the hyperspectral sensing can help not only to classify the seabed material remotely and precisely, but also to construct the continuous geographical information for an effective management and conservation of the coastal area in Korea.

\section{Acknowledgments}

All data for this study was provided by the Korea Hydrographic and Oceanographic Administration (KHOA). The authors gratefully acknowledge the data support and the help of all the contributors to the KHOA.

\section{Author Contributions}

Dongha Lee and Sunhui Sim conceived and designed the research. Dongha Lee led the processing of the CASI classification algorithms, assessment of classification results and manuscript writing. Sunhui Sim assisted with developing the research design, interpreted results and assisted with manuscript revision. All authors contributed with ideas, writing and discussions. 


\section{Conflicts of Interest}

The authors declare no conflict of interest.

\section{References and Notes}

1. Author Freitas, R.; Silva, S.; Quintino, V.; Rodrigues, A.M.; Rhynas, K.; Collins, W.T. Acoustic seabed classification of marine habitats: studies in the western coastal-shelf area of Portugal. ICES Journal of Marine Science 2003, 60, 599-608.

2. Li, Z.D. The Application of hyperspectral data in shallow bottom classification and water depth inversion. Master's Thesis, Guilin University of Electronic Science and Technology, 2010.

3. Deronde, B.; Houthuys, R.; Debrunyn, W.; Fransaer, D.; Van Lancker, V.; Henriet, J.P. Use of airborne hyperspectral data and laserscan data to study beach morphodynamics along the Belgian coast. Journal of Coastal Research 2006, 22(5), 1108-1117.

4. Congalton, R.G.; Green, K. Assessing the Accuracy of Remotely Sensed Data: Principles and Practices (Mapping Science Series). Lewis Publishers, USA, 1998.

5. Melgani, F.; Bruzzone, L. Classification of hyperspectral remote sensing images with support vector machines. IEEE Transactions on Geoscience and Remote Sensing 2004, 42(8), 1778-1790.

6. Hirano, A.; Madden, M.; Welch, R. Hyperspectral image data for mapping wetland vegetation. Wetlands 2003, 23(2), 436-448.

7. Cracknell, A.P. Remote sensing techniques in estuaries and coastal zones, an update. International Journal of Remote Sensing 1999, 19(3), 485-496.

8. ITRES, Hyperspectral Survey Final Report, Technical Report, Korea, December 2010.

9. Wang, Z.; Liu, L. Assessment of coarse-resolution land cover products using CASI hyperspectral data in an arid zone in northwestern China. Remote Sensing 2014, 6(4), 2864-2883.

10. Bertels, L.; Vanderstraete, T.; Van Coillie, S.; Knaeps, E.; Sterckx, S.; Goossens, R.; Deronde, B. Mapping of coral reefs using hyperspectral CASI data; a case study: Fordata, Tanimbar, Indonesia. International journal of remote sensing 2008, 29(8), 2359-2391.

11. Odden, B.; Kneubühler, M.; Itten, K.I. Comparison of a hyperspectral classification method implemented in two remote sensing software packages. University of Zurich, Department of Geography, Remote Sensing Laboratories, Winterthurerstrasse, 190, 2009.

12. ENVI Tutorial : Basic Hyperspectral Analysis. Exelis Visual Information Solutions, Inc., Boulder, CO, USA, 2014. Available online: http://www.exelisvis.com/envi/Hyperspectral_Analysis.pdf (accessed on 13 April 2014).

13. Sulla-Menashe, D.; Friedl, M.A.; Krankina, O.N.; Baccini, A.; Woodcock, C.E.; Sibley, A.; Sun, G.; Kharuk, V.; Elsakov, V. Hierarchical mapping of northren Eurasian land cover using MODIS data. Remote Sens. Environ. 2011, 115, 392-403.

(C) 2014 by the authors; licensee MDPI, Basel, Switzerland. This article is an open access article distributed under the terms and conditions of the Creative Commons Attribution license (http://creativecommons.org/licenses/by/3.0/). 